\title{
Comparison of Soil Moisture Dynamics in Fixed Dune and Sandy Grassland on Korqin Sandy Land
}

\author{
Shuxia $\mathrm{Yao}^{1}$, Chuancheng Zhao ${ }^{1 *}$ \\ ${ }^{1}$ Lanzhou City University, Lanzhou, Gansu, 730070, China
}

\begin{abstract}
Based on the fixed-point observation data of soil moisture in different soil layers $(0 \sim 150 \mathrm{~cm})$ of fixed dunes and sandy grassland in the semi-arid region of Horqin Sandy Land, in the growing season (May to September) from 2005 to 2014, we conducted a comparative study on the seasonal, inter-annual, and spatial dynamics of soil moisture in the two types of sandy land. The results revealed that: (1) in the growing season, the soil moisture in sandy grassland was significantly higher than that in fixed dunes, and the multi-year average soil moisture in both types of sandy land was higher in July than in other months; (2) from 2005 to 2014, the average soil moisture in both types of sandy land was relatively high in 2010, and the average soil moisture in sandy grassland increased gradually with each year; specifically, there was a significant increase in soil moisture in June, while the average soil moisture in fixed dunes did not show an obvious increase; (3) the soil moisture in fixed dunes and sandy grassland generally showed a trend of "first increase, then decrease, and finally increase again", with the increase in soil depth, and this change was more obvious for sandy grassland.
\end{abstract}

\section{Introduction}

As an important component of the hydrological cycle of the Earth's surface system, soil moisture regulates the most basic spatial pattern and process of the land surface system, and connects a series of hydrological, ecological, climatic, and geological processes in the basin, as well as the storage, migration, and transformation of material and energy [1-3]. As an important water source of ecosystems in arid and semi-arid regions, soil moisture directly affects and restricts the growth, distribution, and stability of plants [4-7]. Due to the influence of climate, soil, and other factors, soil moisture is often in a state of dynamic change [8] and varies greatly with different ways of land use.

The Horqin Sandy Land is one of the most severe desertification regions in China. In recent decades, due to the impact of climate change and agricultural development, the water resource constraints in the region have gradually become increasingly prominent. Frequent droughts and declining groundwater level have become important issues affecting the desertification control process [9-10]. Horqin Sandy Land has a fragile ecological environment, however, there have been few comparative studies on soil moisture dynamics in different types of sandy land, and there is also a lack of continuous and systematic observation of soil moisture [11]. This paper uses the fixed-point observation data at different soil depths of fixed dunes and sandy grassland in the semi-arid region of Horqin Sandy Land for 10 consecutive growing seasons, and systematically compares and analyzes the seasonal, inter-annual, and spatial dynamics of soil moisture in these two types of sandy land, with the aim to provide a scientific basis for the effective use and management of soil moisture in this region.

\section{Materials and Methods}

\subsection{Study Area Description}

The study area is located in the southern part of the Horqin Sand Land in eastern Inner Mongolia, China $\left(42^{\circ} 55^{\prime} \mathrm{N}\right.$, $120^{\circ} 42^{\prime} \mathrm{E}$ ). This area has a temperate continental semiarid monsoonal climate. The average annual temperature is $6.5^{\circ} \mathrm{C}$, and annual precipitation is $366 \mathrm{~mm}$. The average annual wind speed is $3.4 \mathrm{~m} \mathrm{~s}^{-1}$. Soils are sandy, light yellow, have loose structure, and are particularly susceptible to wind rosion [12].

\subsection{Study Methods}

In the study area, one special fixed dune and one sandy grassland were selected as the experimental plot, the main vegetation type of sandy grassland was Artemisia scoparia and Setaria viridisthe, and the main vegetation type of fixed dune was Artemisia halodendron and Caragana microphylla. In each plot, three $2 \mathrm{~m}$-deep neutron probes (CNC503DR) were buried at equal distances to obtain the soil volumetric water content (\%) of 8 soil layers, the lower limit of the soil layer is $10 \mathrm{~cm}$, $30 \mathrm{~cm}, 50 \mathrm{~cm}, 70 \mathrm{~cm}, 90 \mathrm{~cm}, 110 \mathrm{~cm}, 130 \mathrm{~cm}$ and $150 \mathrm{~cm}$.

\footnotetext{
*Corresponding author: zhao_chch1978@163.com
} 
From 2005 to 2014, each growth season (May to September), the soil volumetric water content (\%) was conducted once every 7 days and added after rainfall. The soil moisture of each soil layer was measured for 164 times.

Precipitation data for the same period was obtained from the meteorological station of the nearby Naiman Desertification Research Station.

\section{Results}

\subsection{Comparison of monthly changes in SM}

By comparing the changes in multi-year monthly average soil moisture and precipitation at different soil depths of fixed dunes and sandy grassland in the growing seasons from 2005 to 2014 (Fig. 1), it was found that the multiyear monthly average soil moisture of the two types of sandy land did not change much from month to month, however, it was higher in July and lower in May and September for both land types, which was mainly due to the seasonal distribution of precipitation. The soil moisture in the study zone mainly came from precipitation [13], and the monthly average precipitation during the test period was higher in July and relatively lower in May and September (Fig. 1). Overall, the soil moisture in sandy grassland was significantly higher than that in fixed dunes in each month, which is consistent with existing research results [14].

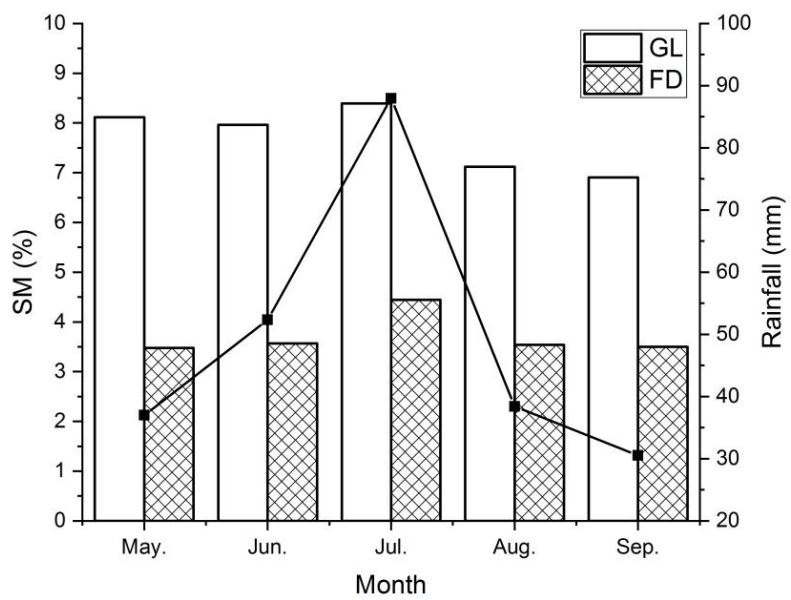

Figure 1. Average SM (\%) of GL and FD and Rainfall (mm) change over month

\subsection{Comparison of inter-annual changes in SM}

The comparison of inter-annual changes in average soil moisture in different soil layers of fixed dunes and sandy grassland in Fig. 2 (F) shows that, from 2005 to 2014, the average soil moisture in sandy grassland increased gradually with each year, while the average soil moisture in fixed dunes did not show an obvious increase. The average soil moisture in both types of sandy land was relatively high in 2010, but the annual average precipitation in 2010 was not the highest among all these years. This shows that the change in soil moisture was not only affected by rainfall, but rather resulted from the comprehensive effects of rainfall, soil surface evaporation, plant transpiration, and other factors.

As can be seen from the inter-annual variation in average soil moisture in different soil layers of the two types of sandy land, from May to September (Fig. 2 $(\mathrm{A} \sim \mathrm{E}))$, the soil moisture in sandy grassland was still significantly higher than that in fixed dunes in each month of the growing season, and the soil moisture in fixed dunes in each month showed small inter-annual variations. However, the soil moisture in sandy grassland in each month showed varying degrees of increase with each year, specifically, the soil moisture in June had a significant increase. From the comparison of soil moisture in different months, the soil moisture in September (Fig. 2 (E)) for the two types of sandy land was lower than that in other months, which was mainly due to high evaporatetranspiration and low precipitation in the growing season. In addition, the soil moisture in fixed dunes in September had the minimum range of inter-annual variation, and showed little difference in other years except for a relatively low level in 2008 . 

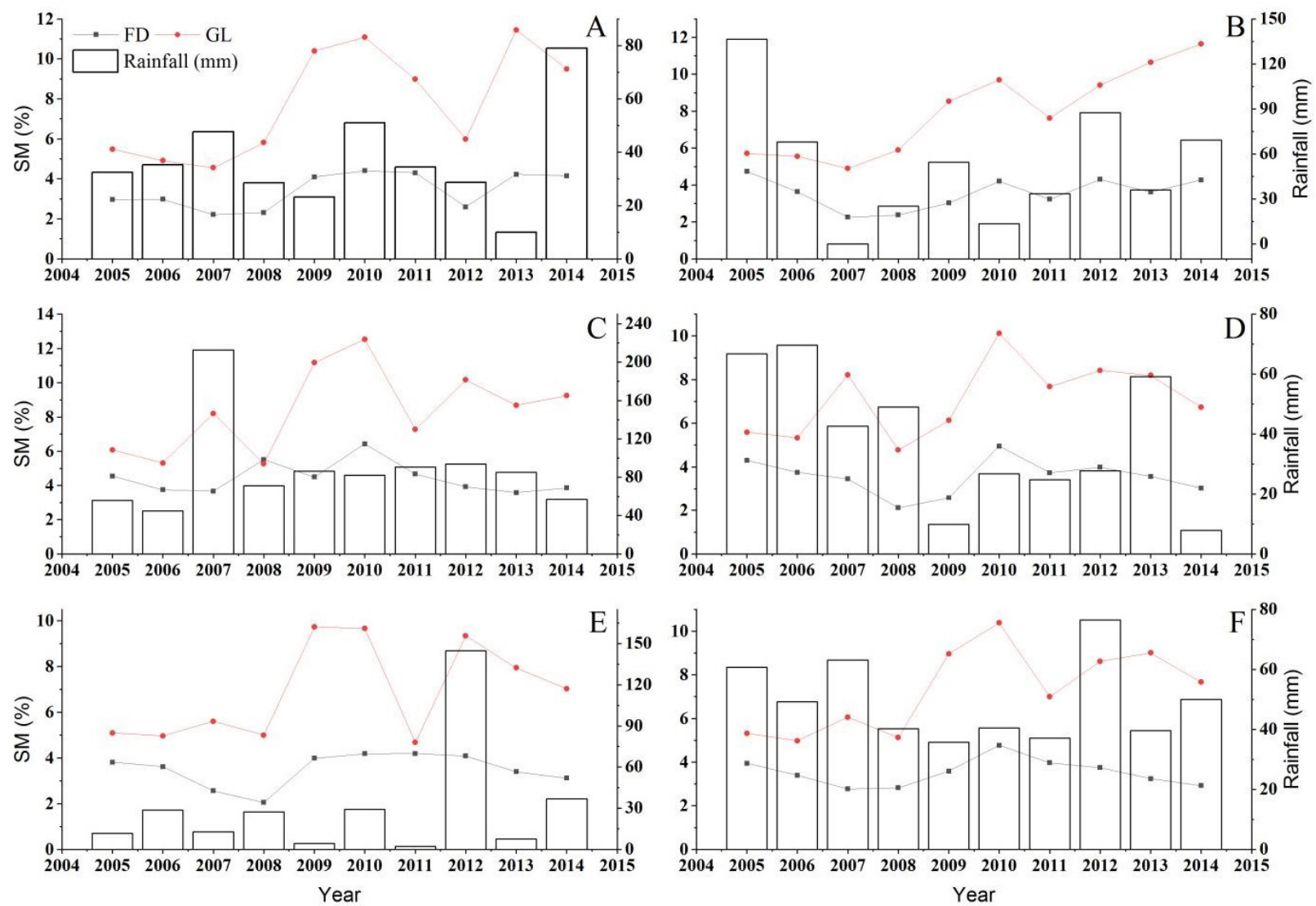

Figure 2. Average SM (\%) of GL and FD and Rainfall (mm) change over year

A-May., B-Jun., C-Jul., D-Aug., E-Sep., F-Average

\subsection{Comparison of spatial changes in SM}

The analysis of the change in average soil moisture with the soil profile of fixed dunes and sandy grassland in the growing season from 2005 to 2014 shows that (Fig. 3), the soil moisture in both, sandy grassland and fixed dunes, showed an inversed S-shaped change with the increase in soil depth, and this change was more obvious for sandy grassland. For the two types of sandy land, the soil profile with a depth range of $0-150 \mathrm{~cm}$ can be divided into four layers: 0-30 cm, 30-70 cm, 70-130 cm, and 130-150 cm. The soil moisture in the $0-30 \mathrm{~cm}$ and $70-130 \mathrm{~cm}$ layers was relatively low, while that in the $30-70 \mathrm{~cm}$ and 130 $150 \mathrm{~cm}$ layers was relatively high. The soil moisture in the two types of sandy land generally showed a trend of "first increase, then decrease, and finally increase again" with an increase in soil depth, which is consistent with existing research results [14-15].

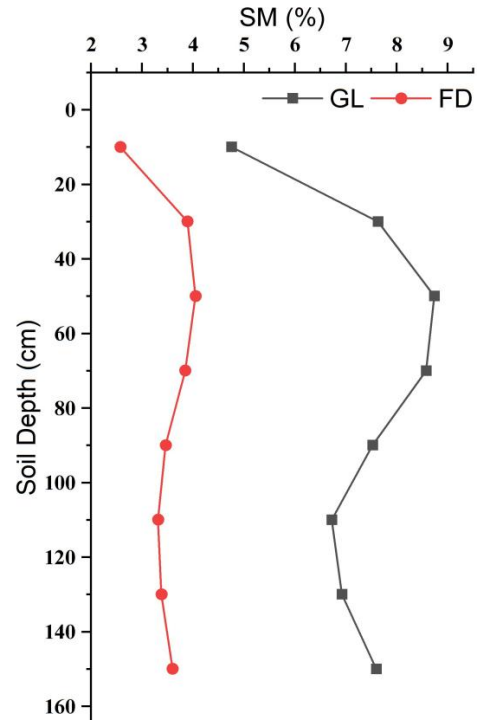

Figure 3. Average SM (\%) of GL and FD change over soil depth

\section{Conclusions}

(1) In the growing season of study area, the soil moisture in sandy grassland was significantly higher than that in fixed dunes and the multi-year average soil moisture was higher in July than in other months. 
(2) From 2005 to 2014, the average soil moisture was relatively high in 2010, and the average soil moisture in sandy grassland increased gradually with each year.

(3) With the increase in soil depth, the soil moisture in two sandy lands were all generally showed a trend of "first increase, then decrease, and finally increase again", and this change was more obvious for sandy grassland.

\section{Acknowledgments}

This study was supported by the National Natural Science Foundation of China (No. 31960273; No. 41771087). The authors also would like to acknowledge the helpful comments and suggestions from anonymous referees.

\section{References}

1. Modeling Soil Processes: Review, Key Challenges, and New Perspectives. Vadose Zone Journal, 2016, 15(5), doi:10.2136/vzj2015.09.0131

2. Q. Zhu, K.H. Liao, X.M. Lai, et al. A review of soil water monitoring and modelling across spatial scales in the watershed, Progress in Geography, 38(8):1150-1158 (2019)

3. J.J. Dai, X.P. Zhang, D.Q. Lv, et al. Dynamic of Soil Water in Cinnamomum camphora Forest in the Red Soil Hilly Region of South China. Research of soil and water conservation, 26(4):123-131 (2019)

4. G.L. Wu, G.H. Ren, D. Wang, et al. Aboveand below-ground response to soil water change in an alpine wetland ecosystem on the Qinghai-Tibetan Plateau, China. Biogeosciences Discussions, 8(4):120-127 (2011)

5. Z. Huang. Research on soil water balance of typical artificial grassland and natural grassland in semi-arid area of the Loess Plateau (2017)

6. Y. Su, L. Chen, Y.F. Li, et al. Temporal and spatial changes of different types of soil moisture in desert steppe. Arid Zone Research, (6) (2018)

7. X.Y. Zhou, T.T. Yang, A.Z. Wang, et al. Distribution characteristics of soil moisture before and after rainfall in dune-dune lowland in Horqin Sandy Land. Chinese Journal of Ecology, (01):157163 (2017)

8. F. Zhang, F.P Zeng, H. Du, et al. Response of soil moisture to precipitation characteristics in different land use patterns in Karst peak-cluster depression area. Ecological Science, 38(5): 38-43 (2019)

9. X.Y. Zhao, C.M. Zhang, X.A. Zuo, et al. Challenges faced by desertification land restoration in Horqin Sandy Land. Journal of Applied Ecology, (07):1559-1564 (2009)

10. Y.L. Li , X.Y. Zhao, X.P. Liu, et al. Research on desertified land and its management to promote ecological restoration and sustainable development of agriculture and animal husbandry in the northern agricultural and pastoral areas. Bulletin of the
Chinese Academy of Sciences, 034(007):832-840 (2019)

11. W. Feng,W. Li , W.B. Yang, et al. Dynamic Response of Soil Moisture to Rainfall in the Pinus sylvestris var. mongolica Sand Fixation Forest of $\mathrm{Mu}$ Us Sandy Land. Research of soil and water conservation, 26(3):101-107 (2019)

12. S.K. Wang, X.Y. Zhao, T.H. Zhang, et al. Effects of several shrubs on rhizosphere microorganisms in Horqin Sandy Land. Arid Area Resources and Environment, , 026(005):140-144 (2012)

13. J.F. Reynolds, P.R. Kemp, K. Ogle, et al. Modifying the'pulsereserve' paradigm for deserts of North America: precipitation pulses, soil water and plant responses. Oecologia, 141, 194-210 (2004)

14. S.X. Yao, T.T. Zhang, C.C. Zhao, et al. Spatiotemporal heterogeneity of soil moisture in different types of sandy land in Horqin area. Journal of Soil and Water Conservation, 26(001):251-254 (2012)

15. C.Y. Zhao, Y.C. Wang. Research on the Temporal and Spatial Dynamics of Soil Moisture in the Marginal Zone of Desert and Oasis. Journal of Soil and Water Conservation, 19(1): 124-127 (2005) 